\title{
Social function of adult men with attention- deficit/hyperactivity disorder in the context of military service
}

This article was published in the following Dove Press journal:

Neuropsychiatric Disease and Treatment

\author{
Gi Moon Noh' \\ Sang Min Lee ${ }^{2}$ \\ Geon Ho Bahn² \\ 'Department of Psychiatry, Kyung Hee \\ University Hospital, Seoul, Republic \\ of Korea; ${ }^{2}$ Department of Psychiatry, \\ Kyung Hee University School of \\ Medicine, Seoul, Republic of Korea
}

Purpose: This study examined the characteristics of adult men with attention-deficit/ hyperactivity disorder (ADHD) on social outcomes with particular focus on social function in the context of military service.

Subjects and methods: Eighty-nine adult male outpatients diagnosed with ADHD in adulthood were included in this retrospective chart review study. Participants were divided into two groups: "military service group (MS)" (those who had completed military duty) and "nonmilitary service group (NMS)" (those who were exempted from conscription or engaged in public service). MS included 50 subjects and NMS included 39 subjects. The age at first ADHD diagnosis, intelligence quotient (IQ), occupation, and psychiatric comorbidities were compared between the two groups.

Results: The age at first diagnosis, IQ, and number of employed participants were significantly higher in MS than in NMS. NMS had significantly more psychiatric comorbidities than those in MS. In both groups, depression was the most common psychiatric comorbidity. Logistic regression analysis showed that the subjects' IQ, psychiatric comorbidity, and age at first diagnosis were determinants of military duty completion.

Conclusion: The results strongly suggested that IQ and psychiatric comorbidities are the most crucial factors affecting military service in male adults with ADHD, independent of ADHD.

Keywords: ADHD, mandatory, army, occupation

\section{Introduction}

Attention-deficit/hyperactivity disorder (ADHD) is a chronic and progressive condition that typically affects children, although symptoms persist into adulthood in $\sim 50 \%$ of cases. ${ }^{1}$ Compared to adults in general population, those with ADHD have reduced occupational ability and adaptability to new environments, increased challenges in interpersonal relationships, more conflicts with family members, and tendency to violate rules or social norms. ${ }^{2-4}$ These characteristics in adults with ADHD cause difficulty in social adjustment. ${ }^{2}$

In adults, jobs are important not only for economic strength but also for determining social status. Adults with ADHD face a disadvantage in this regard, given their poor academic backgrounds and less-developed interpersonal skills, and are therefore more likely to have jobs requiring lower professional skill levels. ${ }^{5-7}$ Compared with chronic mental disorders such as depression, ADHD thus has higher impact on potential employability. ${ }^{8}$ A long-term outcome study revealed that compared with untreated $\mathrm{ADHD}$, treatment for $\mathrm{ADHD}$ may reduce the negative impact on daily life activities. ${ }^{9}$ In addition, recent controversies regarding late-onset ADHD, which
Correspondence: Sang Min Lee; Geon Ho Bahn

Department of Psychiatry, Kyung Hee University School of Medicine, 23 Kyungheedae-ro, Dongdaemun-gu, Seoul 02447, Republic of Korea

Tel +8229588542

Fax +82 29571997

Email maumdoctor@gmail.com; mompeian@khu.ac.kr 
focused on the relationships of ADHD with occupational and social functioning, have revealed no differences in academic backgrounds or occupational expertise between individuals with ADHD and general population. ${ }^{10}$ However, there were not enough reports on the predictors of ADHD from childhood to adulthood. In a recent 33 years' follow-up study, there were no consistent prognosticators of adult function among children with ADHD, except childhood intelligence quotient (IQ). ${ }^{11}$

The military is a highly demanding environment among various forms of social organization. ${ }^{12}$ Several studies have reported negative perceptions of individuals with ADHD in the military, lower functional level; ${ }^{12}$ higher indices of depression, anxiety, and substance abuse ${ }^{13}$ shorter relationship spans $;^{13}$ increased vulnerability to posttraumatic stress disorder; ${ }^{14}$ and lower quality of life. ${ }^{15}$ In Singapore, all male citizens who have reached the age of 18 years are legally mandated to enlist in the military, and those diagnosed with ADHD are assigned to administrative duties that do not provide easy accessibility to firearms, explosives, and ammunition. ${ }^{13}$

Nevertheless, the highly structured training provided in the military might provide a positive environment in which individuals with ADHD can develop organizational skills. ${ }^{16}$ The physical training and exercise required in the military setting might help to reduce the symptoms of ADHD. ${ }^{17}$ In a comparative study of soldiers with and without a history of ADHD in all-volunteer military setting in USA, the rates of retention, promotion, and mental health-related outcomes during a 5-year period demonstrated that those with ADHD could function efficiently in military service. ${ }^{18}$ The voluntary military system in the USA requires candidates with history of stable social function after the age of 14 years and those who are ADHD medication-free for more than 24 months. ${ }^{19}$ There are no exact indicators for the adaptation after commission in the army, and ADHD is not an automatic exclusion criterion.

While adults with ADHD are known to reveal functional challenges in the work setting, there are controversies about key factors affecting social function. In this study, we examined the characteristics of male adults with ADHD, particularly focusing on functional outcomes based on completion of mandatory military service.

\section{Subjects and methods Study design and subjects}

To select the candidates, we retrospectively reviewed the medical records, from January 2007 to June 2017, of Kyung Hee University Hospital and found 139 men who were diagnosed with ADHD in adulthood by a board-certified psychiatrist (Geon Ho Bahn) according to the criteria for ADHD in the Diagnostic and Statistical Manual of Mental Disorders, 4th Edition (DSM-IV). ${ }^{20}$

In the Republic of Korea, men are mandatory to perform military service on reaching the age of 19 years. Following an examination of height, weight, vision, blood pressure, and medical fields (ophthalmology, psychiatry, internal medicine, surgery, otolaryngology, dermatology, urology, and dentistry), conscripts are classified into active duty and nonactive duty groups. Active duty group includes healthy subjects who are deemed suitable for military service. Nonactive duty group includes those with reservist duty and military service exemptions and subjects who were discharged from military service because of accidental disability. Those with reservist duty perform public service instead of military service because of physical and/or mental disabilities. The military service exemption applies to conscripts who are not obligated to serve as soldiers or public service workers because of serious health problems. Therefore, it is essential to record the military service status of adult men on the medical chart at first psychiatry clinic visit. In contrast, women are not considered as candidates for military conscription in the Republic of Korea. Since this study included military service as one of the measurement tools of social outcomes, women were not included.

The inclusion criteria were 1) age of at least 19 years; 2) number of consecutive outpatient visit of more than two times after diagnosed with ADHD; and 3) record of military service such as conscripted or not. Among 139 candidate subjects, 50 subjects were excluded due to the following reasons: 30 subjects with uncertainty about military service information; 6 subjects with pending military classification; 2 subjects with lack of military service obligation because of foreign nationality; and 12 who were eligible but waived from active duty for reasons such as academic work. After a thorough review, 89 subjects were finally included.

\section{Procedures}

Based on completion of active duty service, the subjects were divided into military service group (MS) and nonmilitary service group (NMS). We verified the demographic and clinical characteristics of subjects and compared these between the two groups. Demographic characteristics included the age at diagnosis and occupation. The age at diagnosis was defined as the age at confirmed diagnosis by a psychiatrist. Occupations were classified according to the International Standard Classification of Occupations (ISCO-08) with the following hierarchy of skill level: level 4, professionals; level 
$3+4$, managers; level 3, technicians and associate professors; level 2, clerical support workers, services and sales workers, skilled agricultural, forestry, and fishery workers, and plant and machine operators; and level 1, elementary occupations. ${ }^{21}$ Soldier as occupation under ISCO-08 was excluded because of the study design.

The clinical characteristics included comorbid psychiatric disorders and IQ. Psychiatric comorbidities were assessed using Korean version of Mini-International Neuropsychiatric Interview, ${ }^{22}$ a short, structured diagnostic interview for psychiatric disorders. IQ was measured using Korean-Wechsler Adult Intelligence Score, fourth version (K-WAIS-IV). ${ }^{23}$

This study was approved by the Kyung Hee University Hospital Institutional Review Board (IRB; KMC IRB no 2018-02-009-003). Because all personal and identifiable information of subjects were removed from all data records to ensure confidentiality, the requirement for patients' informed consent was waived by the IRB.

\section{Statistical analyses}

The two groups were compared using either $t$-test or MannWhitney $U$ test, depending on the normality of data. For comparisons of variables between MS and NMS, frequencies were compared using chi-squared test or Fisher's exact test. Multivariable logistic regression was performed to determine the factors that correlated strongly with military service suitability. Statistical analysis was performed using SPSS, version 23.0 (SPSS 23, IBM Corporation, Armonk, NY, USA). For all tests, a $P$-value $<0.05$ was considered to indicate statistical significance.

\section{Results}

The mean age at the time of ADHD diagnosis was significantly higher in MS than in NMS (28.1 \pm 6.2 vs $20.5 \pm 5.7$ years; Table 1). The mean full-scale IQ was significantly higher in MS compared to NMS (109.4 \pm 13.8 vs $87.1 \pm 25.5)$.

The number of employed subjects was significantly higher in MS ( $n=27,54.0 \%)$ than in NMS $(n=12,30.7 \%$; Figure 1). Regarding the distribution of occupations according to skill level, the number of subjects with highly skilled employment was higher in MS than NMS, without statistical significance. The number of unemployed subjects was significantly higher in NMS than in MS (Figure 1).

There were 20 subjects without any comorbid psychiatric disorders (40.0\%) in MS and 4 subjects (10.3\%) in NMS (Figure 2). The mean number of comorbid psychiatric disorders per subject was significantly higher in NMS (1.6 \pm 0.9$)$ than in MS (0.8 \pm 0.7 ; Table 1$)$. In MS, depressive disorder $(n=12,24 \%)$ was the most common psychiatric comorbidity, followed by anxiety disorder $(n=7,14 \%)$ and bipolar disorder $(n=6,12 \%)$. In NMS, depressive disorder $(n=18$, $46.2 \%$ ) was the most common psychiatric comorbidity, followed by autism spectrum disorder, mental retardation, and bipolar disorder ( $\mathrm{n}=7,18 \%$ each). Compared with MS, depressive disorder was significantly more prevalent in NMS (Figure 2).

After controlling for other covariates, the adjusted OR in NMS relative to MS were 0.76 for the age at diagnosis (95\% CI: $0.64-0.91), 0.95$ for IQ (95\% CI: 0.91-0.99), and 6.35 for the number of comorbid psychiatric disorders $(95 \%$ CI: 1.98-20.39; Table 2).

\section{Discussion}

In this study, we identified the significant factors influencing the outcome of adults with ADHD, independent of ADHD. Interestingly, MS had higher age at ADHD diagnosis than NMS. This result did not indicate that subjects in MS had late-onset ADHD. They had displayed ADHD symptoms in childhood, and thus differed from late-onset ADHD in adulthood with the absence of pediatric symptom history. ADHD is underdiagnosed in highly intelligent individuals because high intelligence may mask ADHD problems and associated cognitive deficits. ${ }^{29}$ Such people would accordingly be characterized as late-identified, rather than late-onset, ADHD cases. ${ }^{24}$ The later age of first diagnosis in MS might be attributable to a higher level of intelligence.

Although people with ADHD are known to have impaired occupational functioning, ${ }^{6,25}$ little is known of factors influencing the course of ADHD in adulthood. Life functioning in adulthood including occupation may be influenced by the effects of treatment and nontreatment of ADHD, ${ }^{9}$ and persistence or remission of ADHD. ${ }^{26}$ Although severity

Table I Demographic and clinical characteristics in the MS and NMS groups (mean \pm SD)

\begin{tabular}{l|l|l|l}
\hline & MS & NMS & Value of statistics \\
\hline Age at diagnosis (years) & $28.1 \pm 6.2(n=50)$ & $20.5 \pm 5.7(n=39)$ & $290.05^{\mathrm{a}}$ \\
FSIQ & $109.4 \pm 13.8(n=44)$ & $87.1 \pm 25.5(n=38)$ & $4.8 I^{b}$ \\
Comorbidities per person & $0.8 \pm 0.7(n=50)$ & $1.6 \pm 0.9(n=39)$ & $475.00^{\mathrm{a}}$ \\
\hline
\end{tabular}

Notes: aMann-Whitney $U$ test; ${ }^{b}$-test.

Abbreviations: FSIQ, full scale intelligence quotient; MS, military service; NMS, nonmilitary service. 

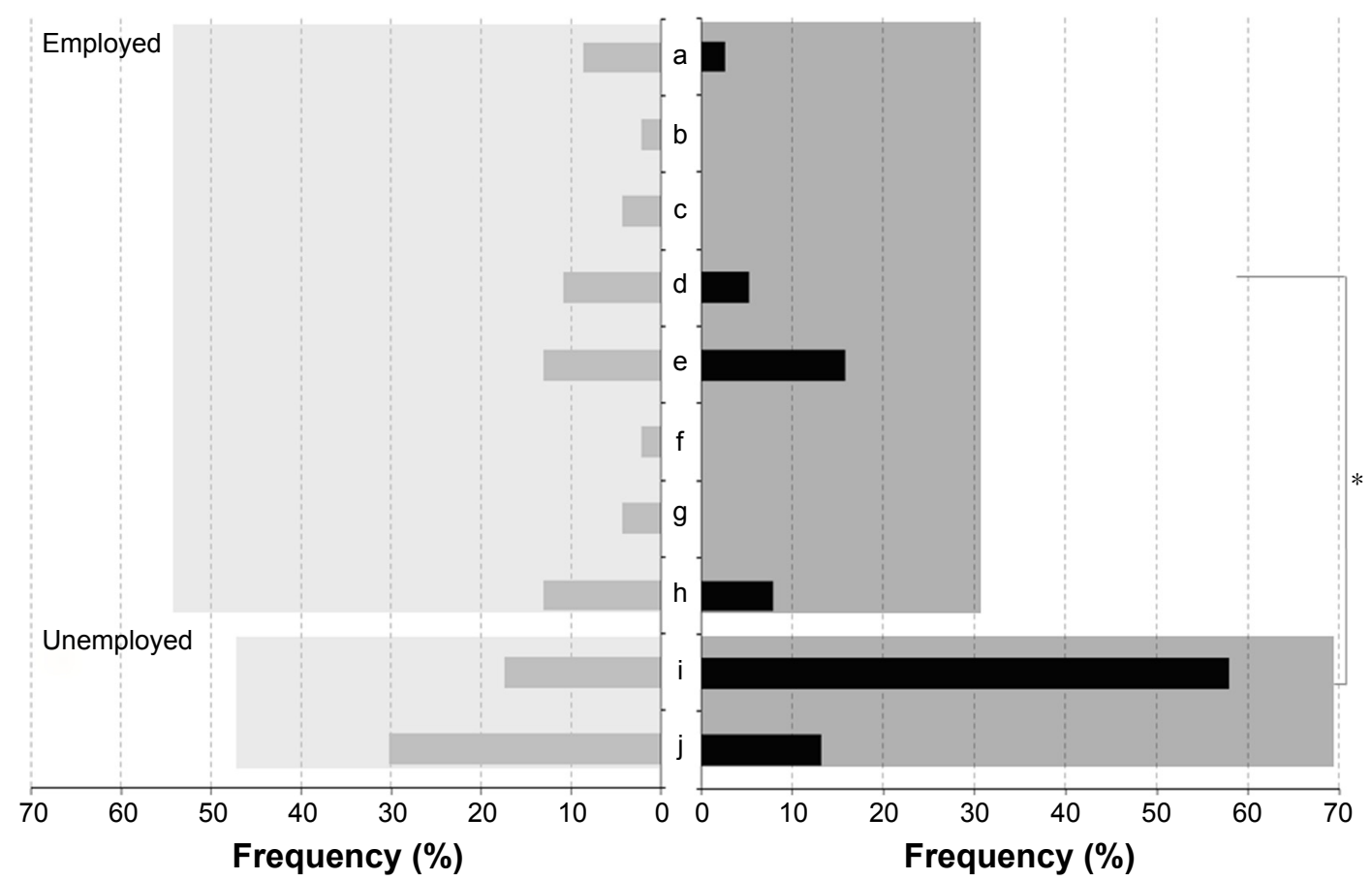

Figure I Distribution of occupations by skill level in the MS and NMS groups.

Notes: Frequency (\%) according to job types compared between MS (gray) and NMS (black). The skill levels are defined as follows: a. professionals; b. managers; c. technicians and associate professors; $d$. clerical support workers; e. services and sales workers; f. skilled agricultural, forestry, and fishery workers; g. plant and machine operators, and assemblers; h. elementary occupations; i. unemployment; and j. students; $* P<0.05$ with Fisher's exact test.

Abbreviations: MS, military service; NMS, nonmilitary service; NOS, not otherwise specified.

of conduct problems in childhood was associated with lower occupational functioning across time, higher IQ in childhood and better social activities in adolescence were associated with a higher occupational ranking in adulthood. ${ }^{11}$
The subjects in MS in this study showed significantly higher rate of employment than that of the subjects in NMS. In case of varying levels of social and occupational functioning among adults with ADHD, personal characteristics would
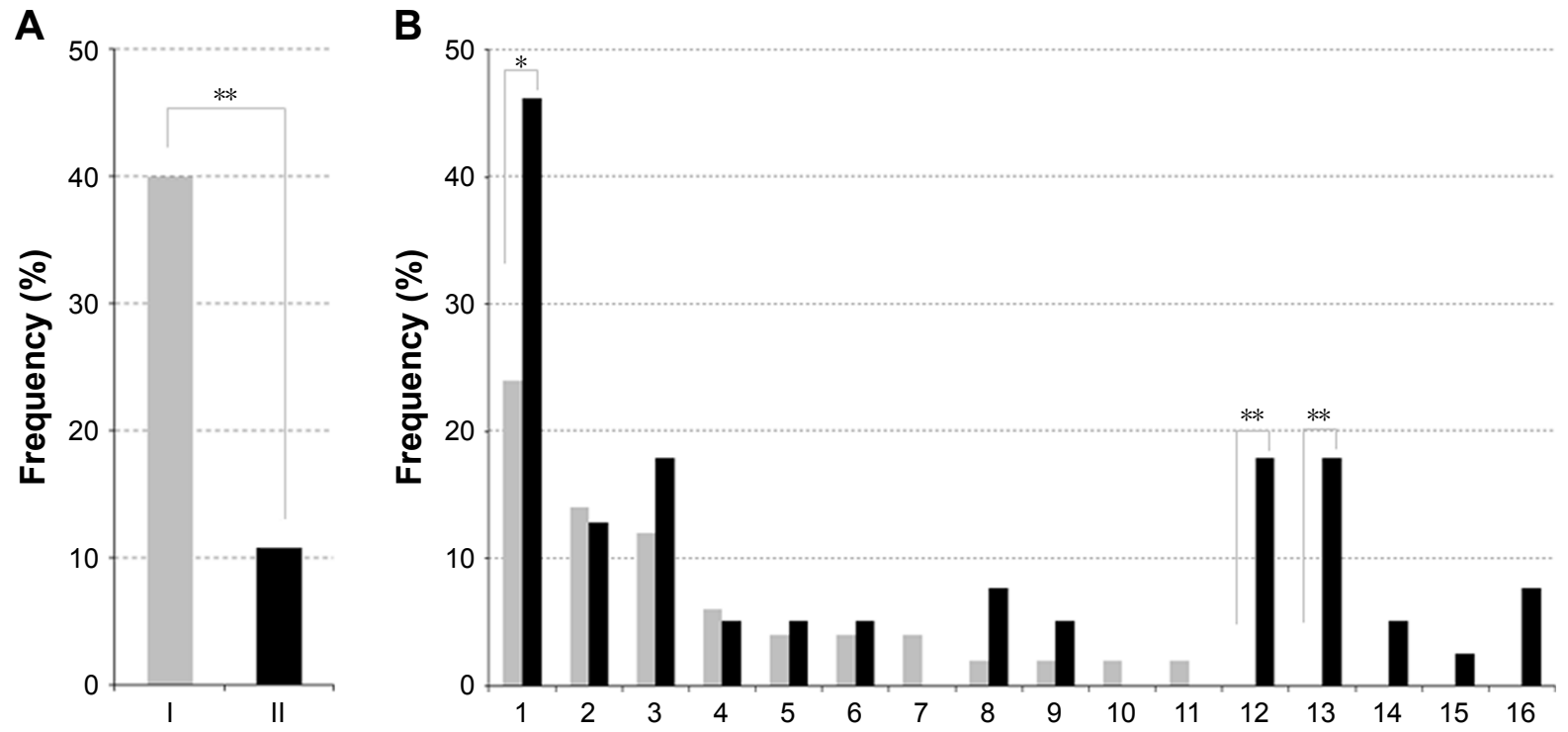

Figure 2 Comorbid psychiatric disorders in the MS and NMS groups.

Notes: (A) Frequency (\%) of no comorbidity compared between MS (I) and NMS (II); (B) frequency (\%) according to various types of comorbidity psychiatric disorders compared between MS (gray) and NMS (black). I. depression; 2. anxiety disorder; 3. bipolar disorder; 4. Tic disorder; 5. habit/impulse control disorder; 6. sleep disorder; 7. substance use disorder; 8. personality disorder; 9. psychoticism; 10. stress-related disorder; I I. somatoform disorder; I2. autism spectrum disorder; I3. mental retardation; 14. conduct disorder; 15. other neurotic disorder; 16. mental disorder NOS. $* P<0.05 ; * * P<0.0$ I was considered statistically significant with Fisher's exact test. Abbreviations: MS, military service; NMS, nonmilitary service; NOS, not otherwise specified. 
Table 2 Effects of demographic and clinical factors on the status of MS

\begin{tabular}{l|l|l|l|l|l|l}
\hline \multirow{2}{*}{ Variables } & \multicolumn{4}{l|}{ Univariable logistic regression (Ref.: I= MS) } & \multicolumn{3}{l}{ Multivariable logistic regression (Ref.: I= MS) } \\
\cline { 2 - 7 } & OR & CI & $P$-value & OR & CI & P-value \\
\hline Age at diagnosis & 0.77 & $0.69-0.87$ & $<0.0001$ & 0.76 & $0.64-0.91$ & 0.0030 \\
FSIQ & 0.94 & $0.91-0.97$ & $0.000 I$ & 0.95 & $0.91-0.99$ & 0.0225 \\
Comorbidity count & 3.61 & $1.91-6.82$ & $<0.0001$ & 6.35 & $1.98-20.39$ & 0.0019 \\
\hline
\end{tabular}

Abbreviations: MS, military service; $\mathrm{FSIQ}$, full scale intelligence quotient.

enable evaluation and treatment planning. Particularly, individual characteristics, such as higher age at diagnosis, higher IQ, and fewer psychiatric comorbidities, as demonstrated in this study, might be predictive of good societal outcomes, despite the presence of ADHD.

Failure to diagnose ADHD is linked to poor prognosis. ${ }^{27,28}$ Relatively common comorbidities yield a population of difficult-to-diagnose and difficult-to-treat adults with undetected underlying ADHD. ${ }^{29}$ In this study, depression was the most common psychiatric comorbidity in both MS and NMS. ADHD and depressive disorders co-occur frequently, with prevalence rates of depression ranging from $18.6 \%{ }^{30}$ to $53.3 \%{ }^{31}$ among individuals with ADHD. ${ }^{31}$ Individuals with comorbid ADHD and depression have high disease burden and lower self-reported quality of life, compared to those with major depressive disorder alone. ${ }^{32}$ Lower prevalence of psychiatric comorbidities may be one of the main reasons explaining the higher proportions of employment among subjects in MS.

IQ has emerged as a potential moderator of the ADHD prognosis. Higher IQ and better socioeconomic status in childhood were each associated with lower ADHD symptoms, as well as with fewer reports of clinical impairment in adolescence and adulthood.$^{33}$ High IQ may be responsible for the slow escalation of ADHD symptoms from childhood through young adulthood. ${ }^{34}$ Children with higher IQ and less severity of ADHD also showed lower compliance to pharmacotherapy for ADHD. ${ }^{35}$ In a recent study identifying predictors of adult functional outcome of ADHD, childhood IQ was positively associated with outcomes in adulthood. ${ }^{11}$ In MS of this study, high IQ was an important potential factor underlying delayed initial ADHD diagnosis, which may not have occurred until after completion of military service.

This study has some limitations in addition to inherent limitation of retrospective chart review. First, the subjects in this study were all males. To generalize the results in this study, further study including adult females with ADHD is needed. Second, we could only determine the subjects' military service status but not how they functioned as soldiers during service. Third, the subjects were recruited from a single university hospital. However, this was advantageous in terms of consistency in diagnosis and treatment policy. To the best of our knowledge, this was the first study to examine the determinants to social outcomes in of adults with ADHD among subjects stratified by military service.

\section{Conclusion}

Adults with ADHD are known to exhibit functional challenges in school and work settings and interpersonal relationships. This study suggests that the military service and current occupation of male adults with ADHD might differ according to the personal characteristics. A higher level of intelligence and fewer psychiatric comorbidities might be predictive of better societal outcomes, despite ADHD.

\section{Clinical implication}

Adults with ADHD who have high intelligence and few psychiatric comorbidities might have good social outcomes, despite having ADHD.

\section{Acknowledgments}

The authors thank Su-Jin Jung of the Statistical Support Department of Kyung Hee University Hospital for assistance with the statistical analysis. This work was supported by the National Research Foundation of Korea (NRF) grant funded by the Korean Government (NRF-2017R1C1B1011036). The corresponding authors had full access to all the data in the study and assume final responsibility for the decision to submit for publication.

\section{Author contributions}

GHB, GMN, and SML were responsible for the study concept and article design. GHB and GMN collected and analyzed the data. GMN and GHB helped in writing the draft. All authors approved the final manuscript and agreement with submission. All authors contributed toward data analysis, drafting and revising the paper and agree to be accountable for all aspects of the work.

\section{Disclosure}

The authors report no conflicts of interest related to this work. 


\section{References}

1. Sibley MH, Mitchell JT, Becker SP. Method of adult diagnosis influences estimated persistence of childhood ADHD: a systematic review of longitudinal studies. Lancet Psychiatry. 2016;3(12):1157-1165.

2. Adler LA. Clinical presentations of adult patients with ADHD. J Clin Psychiatry. 2004;65 (Suppl 3):8-11.

3. Eakin L, Minde K, Hechtman L, et al. The marital and family functioning of adults with ADHD and their spouses. J Atten Disord. 2004; $8(1): 1-10$.

4. Weiss M, Hechtman L, Weiss G. ADHD in parents. J Am Acad Child Adolesc Psychiatry. 2000;39(8):1059-1061.

5. Mannuzza S, Klein RG, Bessler A, Malloy P, Hynes ME. Educational and occupational outcome of hyperactive boys grown up. J Am Acad Child Adolesc Psychiatry. 1997;36(9):1222-1227.

6. Mannuzza S, Klein RG, Bessler A, Malloy P, LaPadula M. Adult outcome of hyperactive boys. Educational achievement, occupational rank, and psychiatric status. Arch Gen Psychiatry. 1993;50(7):565-576.

7. Mannuzza S, Klein RG. Long-term prognosis in attention-deficit/ hyperactivity disorder. Child Adolesc Psychiatr Clin N Am. 2000;9(3): 711-726.

8. Kessler RC, Adler L, Ames M, et al. The prevalence and effects of adult attention deficit/hyperactivity disorder on work performance in a nationally representative sample of workers. J Occup Environ Med. 2005;47(6):565-572.

9. Shaw M, Hodgkins P, Caci H, et al. A systematic review and analysis of long-term outcomes in attention deficit hyperactivity disorder: effects of treatment and non-treatment. BMC Med. 2012;10:99.

10. Halmøy A, Fasmer OB, Gillberg C, Haavik J. Occupational outcome in adult ADHD: impact of symptom profile, comorbid psychiatric problems, and treatment: a cross-sectional study of 414 clinically diagnosed adult ADHD patients. J Atten Disord. 2009;13(2):175-187.

11. Ramos-Olazagasti MA, Castellanos FX, Mannuzza S, Klein RG. Predicting the adult functional outcomes of boys with ADHD 33 years later. J Am Acad Child Adolesc Psychiatry. 2018;57(8):571-582.e1.

12. Fruchter E, Marom-Harel H, Fenchel D, et al. Functioning of young adults with ADHD in the military. J Atten Disord. 2016:1087054716652478.

13. Ng JW, Kwan R, Cheok CC. Clinical and functional outcomes in young adult males with ADHD. J Atten Disord. 2017;21(6):465-474.

14. Lee DY, Lee CS, Park CS, et al. Effect of symptoms of adult attention deficit hyperactivity disorder on symptoms of post traumatic stress disorder in Korean conscripts. Psychiatry Investig. 2012;9(2):154-160.

15. Seo JY, Lee CS, Park CS, et al. Mediating effect of depressive symptoms on the relationship between adult attention deficit hyperactivity disorder and quality of life. Psychiatry Investig. 2014;11(2):131-136.

16. Solanto MV, Marks DJ, Wasserstein J, et al. Efficacy of meta-cognitive therapy for adult ADHD. Am J Psychiatry. 2010;167(8):958-968.

17. Gapin JI, Labban JD, Etnier JL. The effects of physical activity on attention deficit hyperactivity disorder symptoms: the evidence. Prev Med. 2011;52(Supp1 1):S70-S74.

18. Krauss MR, Russell RK, Powers TE, Li Y. Accession standards for attention-deficit/hyperactivity disorder: a survival analysis of military recruits, 1995-2000. Mil Med. 2006;171(2):99-102.
19. Ivanov I, Yehuda R. Optimizing fitness for duty and post-combat clinical services for military personnel and combat veterans with ADHD - a systematic review of the current literature. Eur J Psychotraumatol. 2014;5.

20. American Psychiatric Association. Diagnostic and Statistical Manual of Mental Disorders. 4th ed. Washington, DC: American Psychiatric Association; 1994.

21. International Labour Organization [homepage on the Internet]. Geneva, Switzerland. Available from: http://www.ilo.org/public/english/bureau/ stat/isco/isco08. Accessed January 5, 2018.

22. Yoo SW, Kim YS, Noh JS. Validity of Korean version of the mini-international neuropsychiatric interview. Anxiety Mood. 2006;2(1):50-55.

23. Hwang ST, Kim JH, Park GB, Choi JY, Hong SH. Korean Wechsler Adult Intelligence Scale. 4th ed. (K-WAIS-IV). Daegu (Korea): Korea Psychology; 2013.

24. Chandra S, Biederman J, Faraone SV. Assessing the validity of the age at onset criterion for diagnosing ADHD in DSM-5.J Atten Disord. 2016.

25. Klein RG, Mannuzza S, Olazagasti MA, et al. Clinical and functional outcome of childhood attention-deficit/hyperactivity disorder 33 years later. Arch Gen Psychiatry. 2012;69(12):1295-1303.

26. Agnew-Blais JC, Polanczyk GV, Danese A, Wertz J, Moffitt TE, Arseneault L. Evaluation of the persistence, remission, and emergence of attention-deficit/hyperactivity disorder in young adulthood. JAMA Psychiatry. 2016;73(7):713-720.

27. Spencer T, Biederman J, Wilens T. Attention-deficit/hyperactivity disorder and comorbidity. Pediatr Clin North Am. 1999;46(5):915-927.

28. Pliszka SR. Comorbidity of attention-deficit/hyperactivity disorder with psychiatric disorder: an overview. J Clin Psychiatry. 1998;59(Suppl 7): 50-58.

29. Babcock T, Ornstein CS. Comorbidity and its impact in adult patients with attention-deficit/hyperactivity disorder: a primary care perspective. Postgrad Med. 2009;121(3):73-82.

30. Kessler RC, Adler L, Barkley R, et al. The prevalence and correlates of adult ADHD in the United States: results from the National Comorbidity Survey Replication. Am J Psychiatry. 2006;163(4):716-723.

31. Torgersen T, Gjervan B, Rasmussen K. ADHD in adults: a study of clinical characteristics, impairment and comorbidity. Nord J Psychiatry. 2006;60(1):38-43.

32. McIntyre RS, Kennedy SH, Soczynska JK. Attention-deficit/hyperactivity disorder in adults with bipolar disorder or major depressive disorder: results from the international mood disorders collaborative project. Prim Care Companion J Clin Psychiatry. 2010;12(3).

33. Cheung CH, Rijdijk F, McLoughlin G, Faraone SV, Asherson P, Kuntsi J. Childhood predictors of adolescent and young adult outcome in ADHD. J Psychiatr Res. 2015;62:92-100.

34. Sibley MH, Rohde LA, Swanson JM, et al; Multimodal Treatment Study of Children with ADHD (MTA) Cooperative Group. Late-onset ADHD reconsidered with comprehensive repeated assessments between ages 10 and 25. Am J Psychiatry. 2018;175(2):140-149.

35. Hong M, Lee WH, Moon D, Lee SM, Chung U, Bahn GH. A 36 month naturalistic retrospective study of clinic-treated youth with attentiondeficit/hyperactivity disorder. J Child Adolesc Psychopharmacol. 2014;24(6):341-346
Neuropsychiatric Disease and Treatment

\section{Publish your work in this journal}

Neuropsychiatric Disease and Treatment is an international, peerreviewed journal of clinical therapeutics and pharmacology focusing on concise rapid reporting of clinical or pre-clinical studies on a range of neuropsychiatric and neurological disorders. This journal is indexed on PubMed Central, the 'PsycINFO' database and CAS,

\section{Dovepress}

and is the official journal of The International Neuropsychiatric Association (INA). The manuscript management system is completely online and includes a very quick and fair peer-review system, which is all easy to use. Visit http://www.dovepress.com/testimonials.php to read real quotes from published authors. 